\title{
Concentration of Oleuropein in White Fringe Tree Samples
}

Abbi Vina' 21, Dr. Raymond Dudek

Wittenberg University Chemistry Department

\section{Objective}

Find the best method to accurately measure oleuropein in both concentration and mass for a white fringe tree bark sample.

Introduction

Oleuropein is a polyphenolic compound typically found in the Oleaceae family of plants species. It is most commonly and notably found in olive trees. Oleuropein is known to be a healing component for high blood pressure and cholesterol. This compound may be good for humans but it is a defense mechanism for plants as it acts as a pesticide for insects such as the emerald ash borer (EAB).

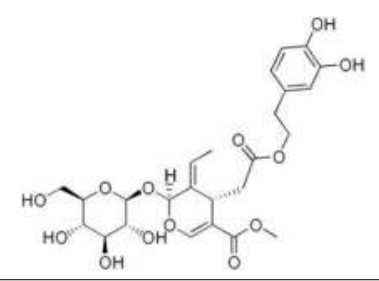

\section{Experimental:}

Standards and Solutions:

- Bark samples: Obtained from various southwestern Ohio locations. Dried for a minimum of two weeks before extraction

- Standard: 0.0503 g Oleuropein concentrate, 5 $\mathrm{mL} \mathrm{MeOH}$, in a $25 \mathrm{~mL}$ volumetric flask

Soxhlet Extraction:

- Round bottom flasks contained: $80 \%$ ethanol and $20 \%$ DI water by mass

- Heating was stared and extraction was run for 2hrs and $40 \mathrm{~min}$

High Performance Liquid chromatography:

- Reverse phase HPLC using acetic acid buffer and methanol as solvents

- Ramping for the method began at $20 \%$ methanol and increasing to $80 \%$ over a 12 minute run time

\section{Results and Analysis:}

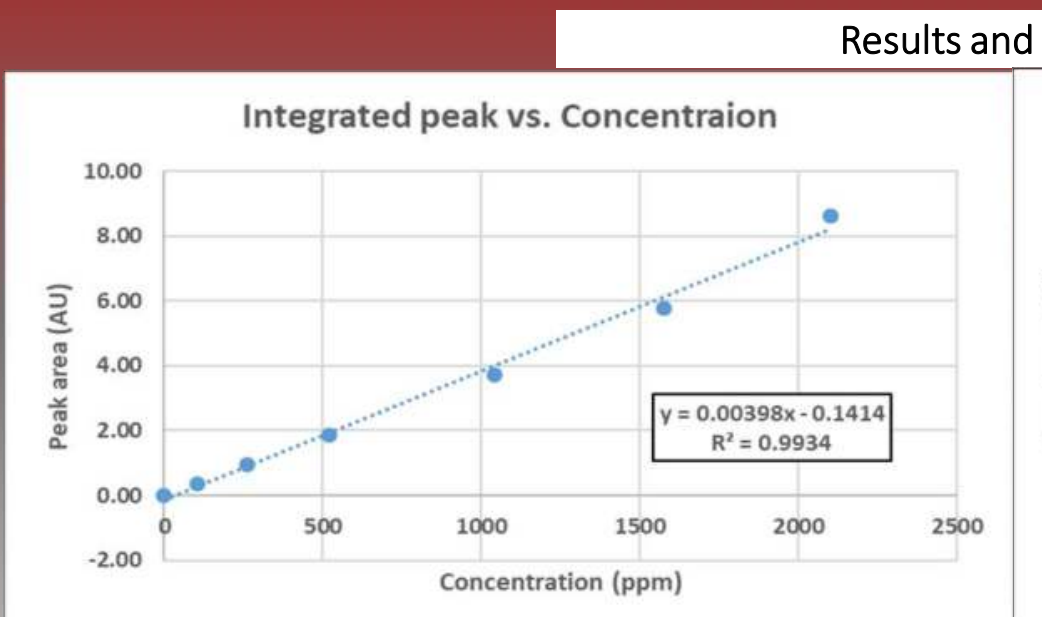

Figure 1. Standard calibrations curve used for calculations.

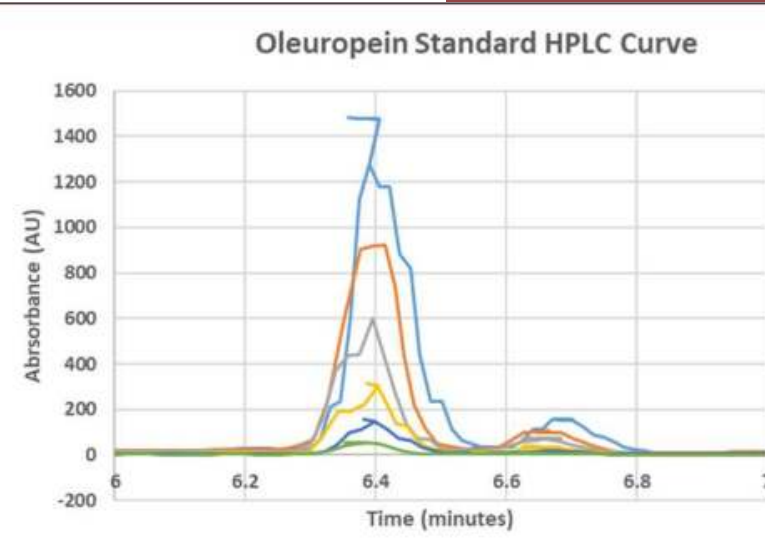

$-2000 \mathrm{ppm}$

$-1500 \mathrm{ppm}$

$-1000 \mathrm{ppm}$

$-500 \mathrm{ppm}$

$-250 \mathrm{ppm}$

$-100 \mathrm{ppm}$

Figure 2. HPLC curves of oleuropein standards

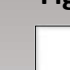

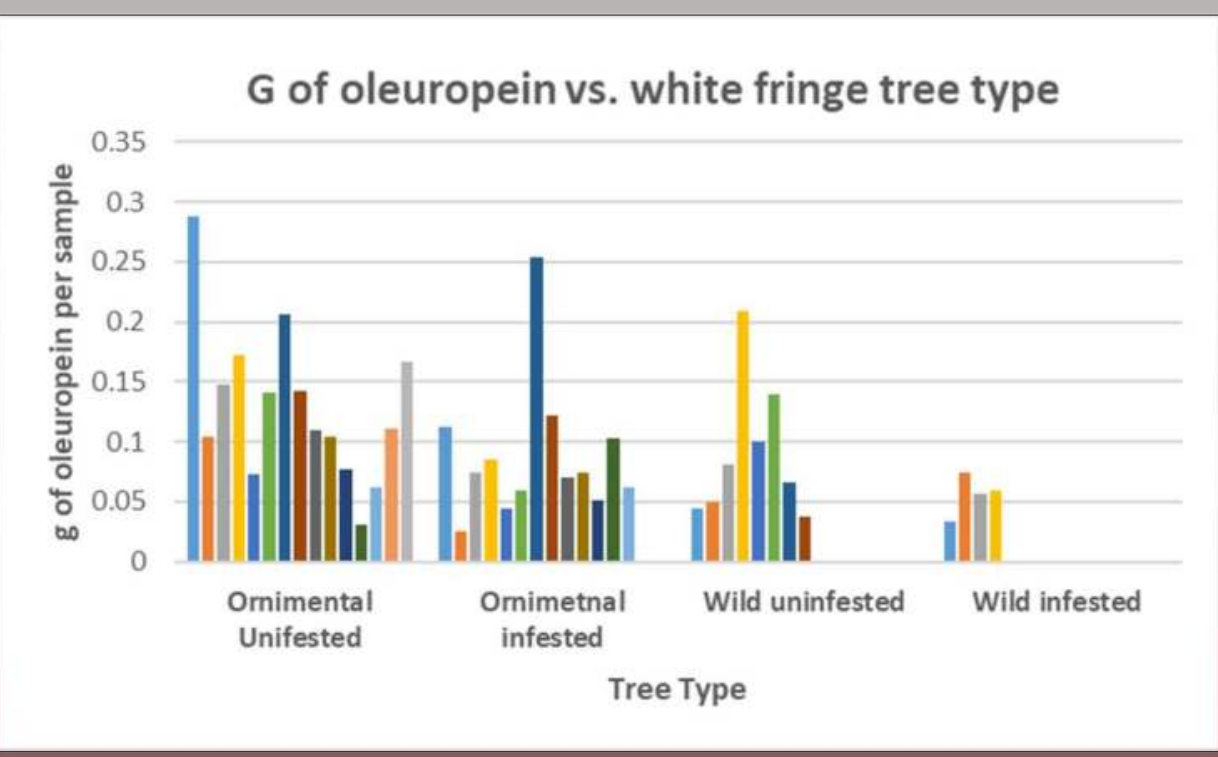

Figure 3. Grams of oleuropein per sample versus tree type

\section{Conclusion:}

Based on the grams of oleuropein per sample of all the samples, it is evident that the ornamental uninfested trees have the highest amounts of oleuropein. Whereas, the lowest amounts can be found in the wild infested tree samples. The results about the wild infested trees indicate that they are more likely to be attacked by the EAB due to the lower levels of oleuropein

\section{Future Work:}

- Continue to improve on technique to more precisely and accurately obtain oleuropein concentrations

- Test more on the effects of time on the sample's decay

\section{Acknowledgments:}

Wittenberg University Chemistry Department Virginia Ellis Franta Endowment Fund

Dr. Don Cipollini

Emily Ellison

\section{Additional Reading}

- Cipollini, D. "White Fringetree as a Novel Larval Host for Emerald Ash Borer." Cipollini, D. "White Fringetree as a Novel Larval Host for Emerald Ash Bor
Journal of Economic Entomology, vol. 108, no. 1, 2015, pp. 370-375., doi:10.1093/jee/tou026.

Konno, K., et al. "Enzymatic Activation of Oleuropein: A Protein Crosslinker
Used as a Chemical Defense in the Privet Tree." Proceedings of the Nation Academy of Sciences, vol. 96, no. 16, 1999, pp. 9159-9164.

doi:10.1073/pnas.96.16.9159.

- Thiemann, Danielle, et al. "The History of Attack and Success of Emerald Ash Borer (Coleoptera: Buprestidae) on White Fringetree in Southwestern Ohio." Environmental Entomology, vol. 45, no. 4, 2016, pp. 961-966. doi:10.1093/ee/nvw073 